\title{
Anabases
}

ANABASES Traditions et réceptions de l'Antiquité

12 | 2010

Varia

\section{Chrystèle BLONDEAU, Un conquérant pour quatre ducs. Alexandre le Grand à la cour de Bourgogne}

\section{Marie Lionnet}

\section{(2) OpenEdition}

\section{Journals}

Édition électronique

URL : http://journals.openedition.org/anabases/933

DOI : 10.4000/anabases.933

ISSN : 2256-9421

\section{Éditeur}

E.R.A.S.M.E.

\section{Édition imprimée}

Date de publication : 1 octobre 2010

Pagination : 244-245

ISSN : 1774-4296

\section{Référence électronique}

Marie Lionnet, «Chrystèle BLondeAu, Un conquérant pour quatre ducs. Alexandre le Grand à la cour de Bourgogne ", Anabases [En ligne], 12 | 2010, mis en ligne le 01 juillet 2011, consulté le 22 septembre 2020. URL : http://journals.openedition.org/anabases/933 ; DOI : https://doi.org/10.4000/anabases. 933

Ce document a été généré automatiquement le 22 septembre 2020

(c) Anabases 


\title{
Chrystèle BLONDEAU, Un conquérant pour quatre ducs. Alexandre le Grand à la cour de Bourgogne
}

\author{
Marie Lionnet
}

\section{RÉFÉRENCE}

Chrystèle BLONDEAU, Un conquérant pour quatre ducs. Alexandre le Grand à la cour de Bourgogne, Paris, CTHS-INHA, 2009, L'art et l'essai, 382 p.

45 euros / ISBN 978-2-7355-0680-4.

1 C'est à une bien vaste entreprise que s'est livrée Chrystèle Blondeau avec cette analyse de la figure d'Alexandre sur les différents supports iconographiques à la cour de Bourgogne. L'étude, d'une grande densité, s'avère d'autant plus ardue que tous les supports ne sont pas conservés ; ainsi en est-il des tapisseries, même si d'autres œuvres permettent de s'en faire une idée. Cette enquête conduit sur plusieurs voies, dont les différentes conclusions permettent d'affiner les conclusions de la thèse.

Dans un premier temps, l'évaluation de la présence d'Alexandre dans la bibliothèque des ducs de Bourgogne signale deux périodes distinctes, celle de Philippe le Hardi et Jean sans Peur, qui connaît le roi macédonien par des citations dans d'autres textes et, ensuite, celle de Philippe le Bon et Charles le Téméraire, qui se distingue par un engouement marqué pour le personnage et une évolution dans sa perception. Sans oublier, dans cette seconde période, la composition de versions bourguignonnes de la légende d'Alexandre.

3 L'analyse minutieuse des manuscrits enluminés permet à $\mathrm{C}$. Blondeau de proposer de nouvelles attributions et de nuancer les conclusions d'autres chercheurs; le Maître de Marie de Bourgogne se voit attribuer plusieurs miniatures dans les Faits et gestes d'Alexandre de Vasque de Lucène. Les contributions multiples au décor des différents ouvrages ouvrent aussi la question de l'organisation du travail. Ainsi, dans le manuscrit 
de Vasque de Lucène, Loyset Liédet apparaît comme un véritable entrepreneur : non seulement il supervise la réalisation du décor - dont l'auteur propose une restitution des différentes étapes (p. 201-204) -, mais il s'occupe aussi de la réalisation matérielle de l'ouvrage (reliure) et de sa remise à son destinataire.

L'auteur évalue ensuite le poids de la matière antique dans la production de cour. Le principat de Philippe le Bon marque indéniablement une évolution dans la diversification des textes et le nombre des tapisseries commandées. Même si elles ont aujourd'hui disparu, ces œuvres déployées à l'occasion des principales cérémonies de la cour affichaient les motivations politiques du duc dans l'usage de l'Antiquité, entre fascination pour l'Orient, revendication d'une ascendance troyenne et projets de croisade. Avec Charles le Téméraire, l'Antiquité devient omniprésente. La production littéraire marque aussi une évolution dans les mentalités: si les œuvres de la bibliothèque de Philippe le Bon, puisant à des sources médiévales, donnent une vision déformée et légendaire de l'Antiquité, comme les Faicts et conquestes d'Alexandre de Jean Wauquelin, Charles le Téméraire soutient l'introduction d'une vision renouvelée de l'Antiquité. Les traducteurs actifs sous son principat adoptent une attitude historique et critique à l'égard des sources, à l'exemple de Vasque de Lucène.

5 Les rapports entretenus par chacun des derniers ducs Valois de Bourgogne avec la figure d'Alexandre - tant dans les textes qu'à travers la structure de leurs décors constituent autant de points d'appui pour affiner la perception et l'utilisation qu'ils ont faites de la matière antique. Pour Philippe le Bon, dans un processus d'identification, Alexandre est outil de légitimation, modèle de chevalerie et de souverain juste, et même - par quelques arrangements avec l'histoire - modèle spirituel. Par ailleurs, Alexandre est rattaché à la Bourgogne et préfigure la reconquête physique et spirituelle de l'Orient. C'est dans cette visée expansionniste que le duc utilisa aussi les tentures en présence du roi de France.

6 Le texte de Vasque de Lucène dresse quant à lui un portrait du souverain macédonien nettement moins idéal. Reconnu habile stratège militaire, ses entreprises apparaissent guidées par l'orgueil. L'auteur montre comment le souverain évolue progressivement vers la tyrannie. Accordant une grande importance aux valeurs militaires, Charles le Téméraire a vraisemblablement puisé dans ce texte des enseignements pour son action militaire et pour engager ses réformes. La figure d'Alexandre lui servit de support pour " élaborer une politique de propagande conquérante, agressive et moderne ».

7 Ces conclusions conduisent $\mathrm{C}$. Blondeau à réapprécier la notion d'humanisme à la cour de Bourgogne. Distinguant nettement le principat de chacun des derniers ducs Valois de Bourgogne, elle reprend les éléments signalant la rupture dans la production littéraire et iconographique marquée par Charles le Téméraire et les indices en faveur de son ancrage persistant dans la tradition médiévale.

8 Si cet ouvrage est remarquable par sa densité et la richesse de ses informations, on ne peut que regretter que plusieurs illustrations soient floues. 


\section{AUTEURS}

\section{MARIE LIONNET}

Historienne de l'art

m.lionnet@orange.fr 